Article

\title{
Development of a Quantitative Model for the Analysis of the Functioning of Integrated Textile Supply Chains
}

\author{
Hua Wang ${ }^{1, *}$, Hafeezullah Memon ${ }^{2,3}\left[\right.$, Syed Hamad Hassan Shah ${ }^{4}(\mathbb{D}$ and \\ Madjidov Shakhrukh ${ }^{5}$ \\ 1 College of Textiles, Donghua University, 2999 North Renmin Road, Shanghai 2011620, China \\ 2 Donghua University Center for Civil Aviation Composites, Donghua University, 2999 North Renmin Road, \\ Shanghai 201620,China; hm@mail.dhu.edu.cn or hafeezullah_m@yahoo.com \\ 3 Key Laboratory of Textile Science \& Technology, Ministry of Education, College of Textiles, \\ Donghua University, 2999 North Renmin Road, Shanghai 201620, China \\ 4 Glorious Sun School of Business and Management, Donghua University, Shanghai 201620, China; \\ hamad74shah@gmail.com \\ 5 Changshu Institute of Technology, 99 South Third Ring Road, Suzhou, Jiangsu 215500, China; \\ shohruh1983@bk.ru \\ * Correspondence: huawang@dhu.edu.cn
}

Received: 28 August 2019; Accepted: 27 September 2019; Published: 8 October 2019

check for updates

\begin{abstract}
The article is devoted to the development of a mathematical model for the analysis of functioning interferonogenic supply chain of textile products. A mathematical model and method of analysis of the functioning of an integrated supply chain of textile products are proposed. A mathematical model contributing to cost reduction in the supply chain of textile products is recommended. The results show that the mathematical model of optimization of placement textile enterprises promotes the decrease of the expenses in the supply chain. The designated model will not only be helpful for managers and enterprises related to textiles, but also for other fields dealing with logistics and supply chains in planning and organization of transport processes.
\end{abstract}

Keywords: logistics; integrated supply chain; mathematical model; textile products

\section{Introduction}

The textile industry has become one of the leading sectors of the global industrial complex [1]. It shares $5.7 \%$ of gross world product, more than $14 \%$ of employment in the industrial complex. Increased trade between the countries and involving new states and territories in the global turnover is changing the world market and enhancing international competitiveness in the sphere of production and market saturation of products in the textile industry, everyday products, and products for technical applications. Today the leaders in the textile industry are considered to be China, and the countries of Central and South-East Asia and also developing rapidly [2]. In these countries, the textile industry was declared as a priority for the development of the national economy. Experts estimate that the manufacturing and developing of these markets will make up a large part of the world economy, a higher share of income growth compared to the economies of the US and Europe [3]. 
Production in developed countries is focused on manufacturing products with the high added price based on high technology, innovation, and quality design, the latest trend in the production of products of high class and technically complicated and unique textiles, including the latest developments in the field of "smart" textiles [4]. In conditions of increased competition, becoming more important in the world market is the competitiveness of products (quality, design, new consumer, medical-biological and functional properties, etc.) [5]. Rising incomes of the population have led not only to increase of sales volume of textile industry goods but also to changes in the assortment structure of the consumption of goods. Today, consumer preferences of the wealthy population switch in favor of more expensive high-quality goods, improved consumer properties, and fashionable design.

Uzbekistan is a country with developed industry. It employs $40 \%$ of the primary production assets of the national economy and more than a million working population. In the formation and development of the industrial complex of Uzbekistan, the central place is covered by the textile industry. In the specific conditions of the Republic, which are considered to be massive agriculture formed in different areas of the textile industry, includes the production of cotton yarn and hosiery, upper and linen knitted fabrics, garments, and so on [6].

The textile industry of Uzbekistan is innovative, an attractive sector of the economy. In this regard, today, the textile industry of the Republic is strategically essential to develop the technology, innovation, and information activity, as these measures will improve the efficiency of enterprises, and ensure their competitiveness. The rapid development of the textile industry and an increase in the export potential of the industry brings the issue of cost optimization in the supply chain of textile products. Figure 1 shows the logistics diagram of the supply chain of textile products in Uzbekistan, by using which the international delivery of textile products is accomplished. As can be seen from the diagram, delivery is carried out in several ways: by the ground and by the sea. In these circumstances, the need arises in the choice of optimum routes of delivery of textile products with minimum costs on all links in the supply chain.

For research and construction methodology of management of all stages of production and transport systems, new principles and approaches reflected in new research areas of logistics and supply chain are needed. Logistics as a methodological science covers production itself, the field of planning, and control of its steps, most critical informational aspects in the chain "supplier-production-customer." It particularly highlights transport links uniting all the above stages of the production process and its informational aspects, by which all the production process is considered as a single system [7]. As evidenced by international experience, a logistic approach will enhance the efficiency of textile enterprises due to coordination of delivery processes of materials and finished products at all stages of the logistics chain: close linkage of the material flow with the manufacturing processes; integrated simulation of the movement of textile materials and use of models to optimize the management of material flow $[8,9]$.

Therefore, efficient transport ensuring the distribution of goods is one of the essential reserves of economizing resources. The above proves the importance of developing research-based models and methodological frameworks for the analysis and planning of the transportation process in logistic supply chains [10]. Herein, we have proposed a mathematical model and method of analysis of the functioning of an integrated supply chain of textile products. This model contributes to cost reduction of textile products in the supply chain. Moreover, this model also optimizes the placements of textile industries and thus promotes the decrease of expenses in the supply chain. 


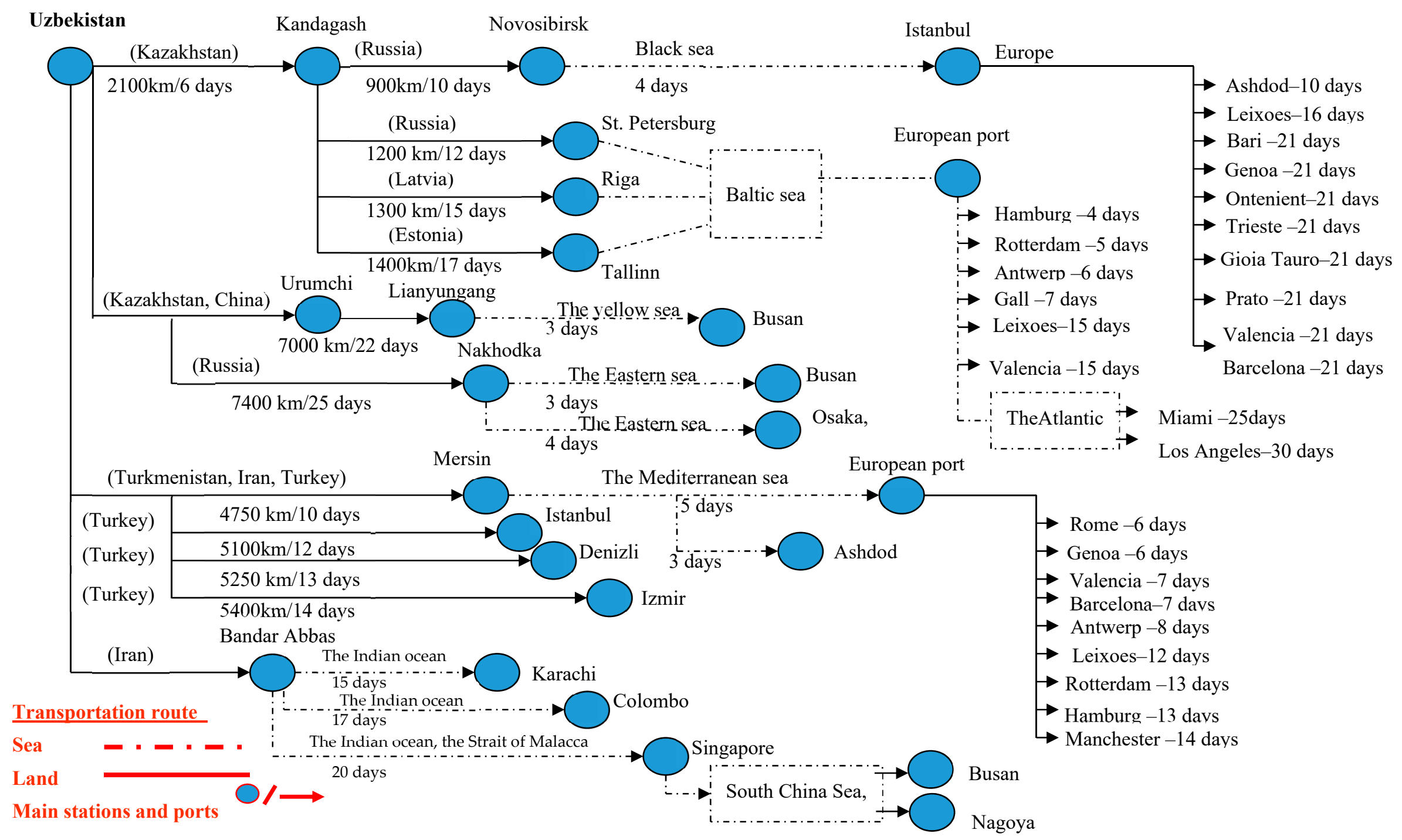

Figure 1. The route of transport corridors of Uzbekistan used for international shipping of textile products. 


\section{Literature Review}

Problems of development of the theory of logistics and supply chain management proved that further progress of the theory and methodology of modeling and integrated planning of supply chain requires structuring and improvement of existing analytical tools. The external environment of logistics operations is continually changing under the influence of market changes and competitive conditions. In order to timely and adequately respond to these changes, any company needs a methodology for systematic planning, design, and reengineering of the logistics system, which allows to take into account the circumstances and evaluate possible alternatives for its development. In logistics of the global format, a new direction is actively developing - the supply chain design. The primary objective of transport companies is to form a logistics chain, to unite all participants in the processes of production, supply, and transport in the unified production and economic system [11]. Moreover, costs directly associated with transportation are, on average, $54 \%$, while cargo operations accounted for $8.5 \%$ of the costs.

Regardless of the number of business processes and each process covered by the business functions, in the first place should be the integration of key business processes across the supply chain and the management of these processes [12]. The development of the methodology of the process approach to modeling and integrated planning in supply chains are (a) the development of competition caused by the transition from seller's market to buyer's market, which served as the impetus for the development of logistics in general and, in particular, the development of information technology relationship management with customers, suppliers, and intermediaries, such as CRM (Customer Relationship Management), SRM (Supplier Relationship Management), and ERM (E-business Relationship Management); (b) the use of approach process as the inter-industry standard for the supply chain management SCOR model (Supply Chain Operations Reference); (3) lack of generalized, hierarchically related mathematical models in the process approach. SCOR-model is a descriptive model, and that is its main flaw. Planning in supply chains requires the application of mathematical models and formal algorithms in the framework of the process approach and SCOR modeling.

In other research, it is mentioned that the modern market describes logistics as the connecting link among market demand, production, and network distribution and delivery tasks of accelerating the movement of material flow along the supply chain [13]. The long process of transportation leads to the fact that the product is outdating morally, barely hitting the market. It is necessary to accelerate the movement of goods, and to make the whole system more flexible, and quickly adaptable to market conditions. To solve the problem of flexibility and adaptation of the logistics system, a tool is needed, which can be used at the pre-planning stage with high precision to predict the result of the logistic chain. This tool should be the method of analysis of logistics supply chains. The proposed method of analysis of the logistics supply chain should reflect the order of calculation, taking into account the pricing of goods and the scheme of routes of the goods delivery. A logistic approach to the analysis of supply production and distribution of products is designed to minimize the total cost of all stages of storage and movement of goods [14].

In the research of [15] for description of participants in the logistics process, methods providing an increase of efficiency of activities through the organization of material flows are provided. A significant part of logistics operations in the path of material flow from the primary source of raw materials to the final consumer is carried out using a variety of vehicles. The costs of these operations reach up to $50 \%$ of the total logistics costs. The priority tasks of transport logistics are noted: collaborative planning of transport processes with warehouse and production; in the case of mixed transportation-joint planning of transport processes for different modes of transport; ensuring technological unity of the transport and warehouse process; determining rational delivery routes.

In the works of [16], new approaches, concepts, and ideas in supply, logistics, and marketing are set out. The problems of transportation control: consolidation of small shipments, tracking, and 
acceleration of transport, forwarding and recognizing, route determination, carrier selection, price determination, and negotiation are being examined.

The development of research area modeling and integrated planning of the supply chain involves three stages. Firstly, the development of the theory by the generalization of scientific research and practical experience. Secondly, the development of methodology understood as studying the structure, organizational logic, methods, and means of activity. Practically, this means that for the solution of specific problems in the subject area required a set of ideas, formal methods, models, and algorithms. Thirdly, the development of techniques to specific tasks, using formal methods, models, and algorithms. However, in the above studies, various aspects of the application of logistics methods are included in supply chain management, but it does not sufficiently take into account various specific features of delivery goods.

Thus, the methodology of the process approach to modeling and integration the supply chain is not entirely developed, which determines the relevance of research in this direction. To solve this problem, first, the business processes and mathematical models describing them should be aligned, a hierarchy of models developed, and those business processes for which there is no adequate mathematical model defined. The next stage is the development of mathematical models, methods, and algorithms of optimization of those business processes for which these models, methods, and algorithms do not exist. Some methodological issues associated with these problems, including models and algorithms for planning and simulation in supply chains, are discussed in the works of domestic and foreign scientists. Others require further theoretical studies that form the basis of new, intellectually-analytical trends in logistics.

\section{A Mathematical Model of Functioning Integrated Supply Chains}

The logistics chain for delivering textile products represent a very complex system for its mathematical description. This, in turn, when implementing the model will require a significant investment of time and money. Herein, we built a mathematical model that accurately described the behavior of the system and would not require much time for programming and computing. From this point of view, it is advisable to use a deterministic approach for the description of the functioning of logistic chains of delivery textile products. This approach is due to the following reasons: ease of calculations, the lack of the necessary statistical data for a sufficiently long period, lack of treatment of probability factors in solving concrete problems of analysis and planning.

Generally, it can be considered that the planning process in real logistic chains has a deterministic character. Moreover, since the information obtained as a result of the analysis is necessary for study planning purposes, the deterministic description of processes in logistic chains of cargo delivery is justified for analysis. Additionally, the representation of decision variables in the model as deterministic quantities satisfies the requirements of the transport service quality (delivery just-in-time).

Functioning of logistic systems has been researched previously [17]. In the result, they instead obtained a complex problem of mathematical programming with continuous variables; the transport process is represented as a linear function, and for building a mathematical model, the methodology of average dynamics is offered. However, the study of mathematical models of authors proves that the real transport process corresponds to the model in the context of classification of transport systems that are set to work.

Consequently, earlier studies of logistics systems are based on a misconception of the nature of the flow transport process, and conclusions about its impact on the efficiency of functioning of the logistic system, in general, are unfounded. As a result, there is a need to develop a mathematical model of functioning transportation logistics systems, which would take into account the peculiarities of the transport process and allow to evaluate its influence on the final result.

Logistics systems usually consists of several subsystems (procurement, production, transport, and consumption). For each phase of the logistics system, where the delivery of textile products 
represents a specific type of transport system, the correctness of the definition depends on the quality and timeliness of transport services.

It should be noted that further, a simple logistics system where the process of its functioning may be a manifestation of three types of transport systems of the lower level is going to be considered. As in the logistics system, the link is working backward that carries information about the formation of demand. Thus, it is quite logical to begin the description of the model with the final consumer of the finished product.

Hence, before one signs a contract for the supply of products by the manufacturer, it is necessary to ascertain the possibility of fulfillment of obligations on production. It is necessary to compare the production capacity of the manufacturer $\left(P_{p r d}\right)$ and the aggregate demand for finished products for all consumers $\left(C_{f p}\right)$ if condition (1) is not satisfied, it is necessary to adjust the plan for the supply of products:

$$
\begin{gathered}
P_{p r d} \geq C_{f p}, \\
C_{f p}=\sum C_{f p_{i}} ; i=1, N,
\end{gathered}
$$

where $P_{\text {prd }}$ is the maximum amount of production; $C_{f p}$-the volume of consumption of finished products; $C_{f p_{i}}$-the volume of consumption of finished products by the $i$-th user; $N$-the number of consumers of finished products.

Then we needed to check the ability to deliver products within the specified time and required quantity, which requires determining the type of transport system in the area "production-consumer," which will allow organizing the delivery of the products to the consumer efficiently. Here, to determine the type of transport system in each link of goods delivery in the logistics chain the following sequence can be used:

1. The route type needs to be set, on which delivery of goods is being done:

- Pendulum with reverse loaded mileage;

- Pendulum with partial load, in reverse directions;

- A pendulum with a full load in a reverse direction;

- Circle.

2. The number of routes $(\mathrm{R})$ that correspond to the number of consumers of finished products in the chain "production-consumer" and the number of suppliers of raw materials on the link "suppliers of production" determined.

3. A solution of the single transport in the link of delivery taking into account the type of route $(\mathrm{Oa} / \mathrm{R})$ calculated.

4. The ability to deliver goods on the route through one transport verified. Therefore, for the link of "production-user" for each consumer of finished products, for a link "supplier-production" for each supplier of raw materials:

$$
\begin{aligned}
& O_{a / R} \geq C_{f p_{i}}, \\
& O_{a / R} \geq O_{r m_{j}} .
\end{aligned}
$$

5. Conclusions about the type of transport system are formed by using the following expression:

$$
R=1, A_{o} \leq 1, R_{r}=1
$$

where $R$-the number of species used routes, unit; $A_{0}$-the number of vehicles in operation, unit; $R_{r}$-the number of riders per revolution on the route, unit. If the conditions of inequality (5) are performed, it is concluded that the presence of a link delivery of a microsystem and further calculations for planning the work of transport on route to perform in the following sequence: 
The length of time the transport will be:

$$
T_{R}=T_{S},
$$

where $T_{S}$ - the duration of operation of the system (hours).

The calculation of the duration of the circulation transport is made according to the formula:

$$
t_{S}=\frac{I_{R}}{R_{T}}+t_{D}
$$

The calculation of the number of drivers with the load during operation of the system is made according to the formula:

$$
R_{r}=\left[\frac{T_{R}}{t_{o}}\right]+R_{p}
$$

where $[X]$ - the integer part of number $X$;

$R_{\mathrm{p}}$-possible execution of the driving for the remaining time $\left(\Delta T_{R}\right)$ obtained after execution of the integer part of $X$. Mathematically possible execution of driving for the rest of the time after a full momentum is defined as the value zero of the variable:

$$
R_{p}=\left\{\begin{array}{c}
1, \text { if } \frac{\Delta T_{R}}{\frac{I_{c}}{R_{t}}} \geq 1 \\
0, \text { otherwise }
\end{array} .\right.
$$

Calculation of the remaining time $\Delta T_{R}$ after running full speed:

$$
\Delta T_{R_{i}}=T_{R}-\left[\frac{T_{R}}{t_{O}}\right] t_{O}, t
$$

Calculating the value of some driving with the load, determines the production of rolling stock for a change:

$$
O=b \sum_{1}^{n} \delta i
$$

where $\delta i$-the coefficient of use of capacities at $i$-th implementation of the $i$-th individual. The value of a daily run rolling stock:

$$
l_{d}=l_{R} R_{r}-l_{w e}+l_{n 1}+l_{n 2}
$$

where $l_{w e}$ - the length of runs without load $(\mathrm{km})$. so that:

If requirements of the contract for product delivery by the manufacturer satisfy the requirement,

$$
R=R_{i}, i=1 \ldots 6, A_{O} \leq 1, R_{r}>1,
$$

where $R_{i}$-the sequence number of the route to link the delivery of goods in the logistics system.

Planning the route of transport is easy to implement using a methodology for a minimal system, according to which the duration, performed using the formula, determines turnover of rolling stock:

$$
t_{c}=\frac{l_{R}}{R_{t}}+\sum_{1}^{n} t_{D_{i}}
$$

The formula accepts the calculation of the number of the riders during operation of the system:

$$
R_{r}=\left[\frac{T_{R}}{t_{O}}\right] n+R_{p f}
$$

where $n$ - the number of driving per turnover. 
The formula determines the number driving:

$$
R_{p f}=\left\{\begin{array}{c}
k, \text { if } \frac{\Delta T_{R}}{\frac{\sum_{1}^{n} C_{i}+\sum_{1}^{r} l w w_{j}}{R_{t}}+\sum_{1}^{k} t_{D_{i}}} \\
\ldots \ldots \ldots \ldots \ldots \ldots \ldots \ldots \ldots \ldots \ldots \ldots \ldots \ldots \ldots \\
1, \text { if } \frac{\Delta T_{R}}{\frac{I_{C}}{R_{t}}+t_{D_{j}}} \\
0, \text { otherwise }
\end{array} .\right.
$$

where $r$-the number of idle parts of the route, which must pass the transport to carry $k$-driving with the cargo.

The amount of rest time is determined by Equation (10), later, the next generation of rolling stock is determined according to Equations (12) and (13).

The length of a daily run:

$$
l_{d}=l_{R}\left[\frac{T_{R}}{t_{C}}\right]+\sum_{1}^{R_{p f}} l_{C_{i}}+\sum_{1}^{r} l_{w e_{j}} .
$$

In the case when the conditions under which:

$$
R=R_{i}, i=1 \ldots 7, A_{O}>1, R_{r}>1 .
$$

The planning of transports on the routes should be performed according to the method for a small system. Small systems are divided into saturated and unsaturated. For such a system, the saturation moment is determined by the following equality:

$$
I_{m}=R h,
$$

where $I_{m}$ - the interval of movement of transport (hours);

$R h$ - the rhythm of the system $(1 \mathrm{~h})$.

$$
I_{m}=\frac{t_{C}}{A_{O}}
$$

The calculation of the turnaround time of transport is made according to Equation (14). The rhythm of operation of the system is equal to the value of the rhythm of loading (unloading) works $R h_{l j}$ in $j$-th of the points where it is maximum:

$$
\begin{gathered}
R h=\max \left\{R h_{l j} ; R h_{u j}\right\}, \\
R h_{l(u) j}=\frac{t_{l(u) j}}{X_{l(u) j}},
\end{gathered}
$$

where $X_{l(u) j}$-the number of posts in the $j$-th point of loading (unloading), $j=1, n$.

To avoid the first queues in points of loading (unloading) the issue of transport must be carried out by the duration of the rhythm system. Then, given that all of the transports systems are closed at the same time, the planned duration of any transport system depends on the ordinal number, under which he goes to the routes:

$$
T_{R_{i}}=T_{S}-R_{\max }(i-1) .
$$

where $T_{S}$ - the planned duration of the system (hours);

$i$-the ordinal number of the transport.

The length of the turnover of the transport is determined by Equation (14), a calculation of the driving amount of the $i$-th transport during a stay in the system by the formula:

$$
R_{r_{i}}=\left[\frac{T_{R_{i}}}{t_{O}}\right] n+R_{p f_{i}}
$$


where $R_{p f_{i}}$-the number of driving of the $i$-th transport for the remainder of the time after performing the rotations on the route.

The quantity of $R_{p f_{i}}$ can take the following values:

$$
R_{p f_{i}}=\left\{\begin{array}{c}
k, \text { if } \frac{\Delta T_{R_{i}}}{\frac{\sum_{1}^{k} l_{j}+\sum_{1}^{f} l v_{s}}{R_{t}}+\sum_{1}^{n} t_{D_{j}}} \geq 1 \\
1, \text { if } \frac{\Delta T_{R_{i}}}{\frac{R_{C_{i}}}{R_{t}}+t_{D}} \geq 1 \\
0, \text { otherwise }
\end{array},\right.
$$

where $f$-the number of idle parts of the route, which must pass the transport to carry $k$ driving with the cargo.

The amount of rest time after running full speed:

$$
\Delta T_{R_{i}}=T_{R_{i}}-\left[\frac{T_{R_{i}}}{t_{O}}\right] t_{O}
$$

The formula determines the development of the $i$-th transport in the small system:

$$
O_{i}=b R_{O} \sum_{1}^{k} \delta i+b \sum_{1}^{k} \delta j .
$$

The required number of vehicles for transport under consideration the small system is calculated according to a particular procedure, based on the fact that the declared volume of traffic should not exceed the total production transport.

$$
O_{L} \leq \sum O_{i}
$$

The procedure of calculations is as follows:

- calculating the number of the first driving out on the routes, transport;

- determined the amount of cargo 01 that can be delivered by the first transport;

- compared $O 1$ and $O_{L}$, if the $O_{L}>01, O 2$ is calculated and determined $O 2+O 1$, and so on until the amount will satisfy the condition (28).

The development of the system for time $T_{S}$ :

$$
O_{s}=\sum O_{i}
$$

The run for changing all transports that serve the system:

$$
L_{c a t}=\sum_{1}^{n}\left(L_{R} R_{r_{i}}-L_{C}\right) .
$$

After determining the type of transport system in the delivery link of finished products, it is necessary to calculate the throughput $\left(O_{S f p}\right)$ on each route of a logistics chain "production-consumers" and compare with the required volume of supplies to consumers $\left(C_{f p}\right)$ :

$$
O_{S f p} \geq C_{f p_{i}} .
$$

If the condition (31) fails, it means the inability to deliver products in the required amount under the existing parameters of the transport system, which ultimately will lead to the increased cost of 
production at the end of the logistic chain. The failure of condition (31) will lead to increased cost and construction time of the object.

The next step is the calculation of need in every kind of raw material for production claimed by consumers $\left(C_{f p} i\right)$ :

$$
O_{r m_{j}}=O_{j} \times C_{f p_{i}} .
$$

Next, the production of the first transport, per the route type, for each supplier of raw materials is to be determined and compared with the raw materials for production:

$$
O_{1 a / R} \geq O_{r m_{j}}
$$

Inequalities (5), (13), (17) define the type of transport system on the link "suppliers of raw materials-production" and the bandwidth $\left(O_{s . r m}\right)$ for each route of the system.

If the planned amount of supply of raw materials exceeds the throughput on this route $\left(O_{r m_{j}} \geq O_{s . r m}\right)$, it is necessary to calculate the level of reduction in plan production according to the formula:

$$
\Delta P_{p r d}=C_{f p}-\left(\frac{O_{s . r m_{j}}}{O_{r m_{j}}}\right) .
$$

The reduction of the production plan, in connection with the shortfall of raw material, will cause a rise in the price of production at the end of the logistic chain. If the throughput of the system in the delivery of raw materials allows meeting the needs of the manufacturer, making a timetable of transports on the route and, if necessary, the schedule of release, then move on to the final stage of calculation of production costs at the end of the logistic chain. In contrast to the currently used mathematical apparatus, in the calculation of indicators of functioning logistics systems, this model takes into account the discrete nature and the behavior of the transport process in areas of delivery [18].

\section{Results}

In this study the analysis of logistics and supply chains of textile products was in the Eastern direction (Figure 1). All the numerical data was collected from the Research Center at Tashkent Institute of Textile and Light Industry, Uzbekistan. The logistics diagram of the supply chain of textile products was examined, depending on the time of their promotion. Annual turnover or the number of flights and journeys on the route Tashkent (Uzbekistan)-Almaty, Zharkent (Kazakhstan)-Urumqi (China), (L) was determined by 365 days per year and the total time of the turnover of goods $\sum t$ :

$$
L=\frac{365}{\sum t} .
$$

The total turnaround time is defined as the sum of the processing time of orders from buyer and seller, the transport time in international communication, and the time the goods were in the warehouse (including shipping time), as well as the time spent by the goods at the place of retail trade.

The formula determines the amount of inventory or the average size of delivery per flight and journey, Vm.i. for each alternative delivery option:

$$
V_{\text {m.i. }}=\frac{V_{s}}{L}
$$

where $V s$ - the volume of sales, dollars, or unit goods.

The cost of transporting per flight and journey with each mode of transport for each sales volume is defined as follows:

$$
C=\frac{C_{s p} \times V_{s}}{L} \text {; or } C=C_{s p} \times V_{m . i .} .
$$

Total costs per flight and journey with the delivery of the goods for each of the alternative schemes for the delivery costs include shipping and cost of inventories. 
The costs of inventories are determined by the $C_{s t}$, depending on the transport time $t$ and the time when the product is in stock $t w$ :

$$
C_{s t}=V_{m . i .} \times r \times \frac{t+t_{w}}{365},
$$

where $r$ is the percentage rate on the stock value, $\%$.

Studying this example:

1. The volume of demand for textile products is a sufficiently stable and regular character.

2. Sales of $-615,384$ USD 79,000 or units per year; $-461,538$ USD, or 59,251 units per year; —384,615 USD, or 49,376 units per year; -192,308 USD, or 24,688 units per year.

Sale of textile goods is carried out uniformly by the day.

3. An alternative scheme of delivery goods:

(1) Transportation by plane in small containers to the place of retail trade;

(2) Road transportation in small containers to the place of retail trade;

(3) Road transportation in large containers to the place of retail trade;

(4) Transportation by railway in large containers to the warehouse and from small batches to retail outlets.

4. The time during plane transportation: request processing time- 6 days; travel time -1 day; time spent at the place of retail trade-2 days.

5. The required time for transportation by vehicles transport in small containers: request processing time - 6 days; in 3 days; time kept in retail-3 days.

6. The required time for the transportation by vehicles large containers: request processing time -6 days; in 3 days; time kept in retail-9 days.

7. The required time for carriage by railway, in large containers to the warehouse and then in small batches: request processing time -6 days; time 5 days; the time spent on stock-10 days; the residence time in the place of retail trade -6 days.

8. Specific transport costs:

(1) During sales volume of 615,384 USD or 79,000 units. By different means of transportations: plane 0.051 USD; vehicles of small containers 0.042 USD; vehicles of large containers $0.024 \mathrm{USD}$; railway $0.003 \mathrm{USD}$.

(2) During sales volume, 461,538 USD, or 59,251 units. By different means of transportations: plane 0.063 USD; vehicles of small containers 0.051 USD; vehicles of large containers 0.036 USD; railway 0.018 USD.

(3) During sales volume of 384,615 USD or 49,376 units: By different means of transportations: plane 0.07 USD; vehicles of small containers 0.056 USD; vehicles of large containers 0.044 USD; railway of 0.027 USD.

(4) During sales volume of 192,308 USD or 24,688 units: By different means of transportations: plane USD 0.087; vehicles of small containers 0.082 USD; vehicles of large containers 0.079 USD; railway 0.063 USD.

9. The percentage rate on the cost of inventory is $10 \%$ per annum.

10. The cost of one unit of the commodity is 7789 USD.

Defined by:

- Annual turnover or number of flights and journeys for each scheme of delivery and each sale;

- Amount of inventory or the average size of delivery per trip (from the economic point of view, goods in transit constitute inventory); 
- Cost of transporting per flight and journey by each means of transport for each sale;

- The overall cost per flight and journey with the delivery of goods for each of alternative delivery schemes, including costs for inventories;

- $\quad$ Rational schemes of goods delivery for each sale.

Solution: calculations are summarized in Table 1.

Table 1. Choice of logistics diagram of the supply chain of textile goods depending on the time of their transportation.

\begin{tabular}{|c|c|c|c|c|}
\hline Indicators & By Plane & $\begin{array}{l}\text { By Vehicles } \\
\text { of Small } \\
\text { Containers }\end{array}$ & $\begin{array}{l}\text { By Vehicles } \\
\text { of Large } \\
\text { Containers }\end{array}$ & By Railway \\
\hline The request processing time, days & 6 & 6 & 6 & 6 \\
\hline Time of transportation of goods, days & 1 & 3 & 3 & 5 \\
\hline $\begin{array}{l}\text { The time of the goods in the } \\
\text { warehouse, days }\end{array}$ & 0 & 0 & 0 & 10 \\
\hline $\begin{array}{l}\text { The residence time of the goods at the } \\
\text { place of retail trade, days }\end{array}$ & 2 & 3 & 9 & 6 \\
\hline The total time of turnover, days & 9 & 12 & 18 & 27 \\
\hline Annual turnover & 4056 & 3042 & 2028 & 1352 \\
\hline $\begin{array}{l}\text { The amount of inventory or the } \\
\text { average size of delivery per flight and } \\
\text { journey, when the alternative schemes } \\
\text { for the delivery of goods, USD }\end{array}$ & $\begin{array}{c}1,517,219 \\
1,137,914 \\
948,262 \\
474,132\end{array}$ & $\begin{array}{c}2,022,959 \\
1,517,219 \\
1,264,349 \\
632,176\end{array}$ & $\begin{array}{c}3,034,438 \\
2,275,828 \\
1,896,524 \\
948,264\end{array}$ & $\begin{array}{l}4,551,657 \\
3,413,743 \\
2,844,786 \\
1,422,396\end{array}$ \\
\hline $\begin{array}{l}\text { Unit costs for transportation for } \\
\text { alternative schemes of goods } \\
\text { delivery, USD }\end{array}$ & $\begin{array}{c}0.051 \\
0.063 \\
0.07 \\
0.087\end{array}$ & $\begin{array}{l}0.042 \\
0.051 \\
0.056 \\
0.082\end{array}$ & $\begin{array}{l}0.024 \\
0.036 \\
0.044 \\
0.079\end{array}$ & $\begin{array}{l}0.003 \\
0.018 \\
0.027 \\
0.063\end{array}$ \\
\hline $\begin{array}{l}\text { The cost of transporting per flight and } \\
\text { journey under alternative schemes } \\
\text { delivery of goods, USD }\end{array}$ & $\begin{array}{c}1,547,563 \\
1,433,772 \\
1,327,567 \\
824,990\end{array}$ & $\begin{array}{l}1,699,286 \\
1,547,563 \\
1,416,071 \\
1,036,769\end{array}$ & $\begin{array}{l}1,456,530 \\
1,638,596 \\
1,668,941 \\
1,498,257\end{array}$ & $\begin{array}{c}273,099 \\
1,228,947 \\
1,536,184 \\
1,792,219\end{array}$ \\
\hline $\begin{array}{l}\text { The cost of stocks for the flight and } \\
\text { journey under alternative schemes for } \\
\text { the delivery of goods, USD }\end{array}$ & $\begin{array}{l}4157 \\
3118 \\
2598 \\
1299\end{array}$ & $\begin{array}{c}16,627 \\
12,470 \\
10,392 \\
5196\end{array}$ & $\begin{array}{c}24,941 \\
18,705 \\
15,588 \\
7794\end{array}$ & $\begin{array}{c}187,054 \\
140,291 \\
116,909 \\
58,455\end{array}$ \\
\hline $\begin{array}{l}\text { Total cost per flight and journey under } \\
\text { alternative schemes of delivery of } \\
\text { goods, USD }\end{array}$ & $\begin{array}{c}1,551,720 \\
1,436,889 \\
1,430,165 \\
826,289\end{array}$ & $\begin{array}{l}1,715,913 \\
1,560,034 \\
1,426,463 \\
1,041,965\end{array}$ & $\begin{array}{l}1,481,471 \\
1,657,302 \\
1,684,529 \\
1,506,051\end{array}$ & $\begin{array}{c}460,154 \\
1,369,238 \\
1,653,093 \\
1,850,674\end{array}$ \\
\hline
\end{tabular}

Thus, when the volume of sales, amounting to 615,384 USD, 461,538 USD based on the principle of minimizing total costs, it is advisable to transport the textile goods by railway, delivery of textile products in the amount of 384,615 USD by vehicles in small containers, and upon delivery of the goods in the amount of 192,308 USD by plane transport.

\section{Conclusions}

In the practice of transport organizations today, there is a need for a mathematical and methodological tool for ensuring high-quality analysis and planning activities of vehicles in the logistic supply chain. Successful realization of the planned directions will allow solving significant scientific and practical problems that will create the conditions for science-based planning and 
management of rolling stock on the links of the logistics supply chain. Results obtained after computer modeling should be explained (described) and analyzed. Based on the analysis, evidence-based guidelines for planning are produced for the rational values of work of rolling stock on parts of the delivery of goods in the logistics system of textile products; the rational number of vehicles of sufficient capacity; and the formation of reasonable targets for each participant in the logistics chain at the level of service. The described model will help managers of enterprises in planning and organization of transport processes, especially as a mathematical and methodological tool for analysis and planning activities in the logistic supply chain, not only for textile products. Moreover, the described model can decrease the costs of the supply chain functioning by comparison and choice of the right way for the realization of transport. However, in practice, such analyses are more complex.

Author Contributions: Conceptualization, H.W., and M.S.; Methodology, H.W.; Validation, H.W., M.S., and H.M.; Formal Analysis, H.M., S.H.H.S. and M.S.; Investigation, M.S.; Writing-Original Draft Preparation, M.S. and H.M.; Writing-Review \& Editing, H.M., and S.H.H.S.

Funding: This research received no external funding.

Conflicts of Interest: The authors declare no conflict of interest.

\section{References}

1. Memon, H.; Khatri, A.; Ali, N.; Memon, S. Dyeing recipe optimization for eco-friendly dyeing and mechanical property analysis of eco-friendly dyed cotton fabric: Better fixation, strength, and color yield by biodegradable salts. J. Nat. Fibers 2016, 13, 749-758.

2. Peng, L.; Zhang, Y.; Wang, Y.; Zeng, X.; Peng, N.; Yu, A. Energy efficiency and influencing factor analysis in the overall Chinese textile industry. Energy 2015, 93, 1222-1229. [CrossRef]

3. Altman, R.C. The fall and rise of the West: Why America and Europe will emerge stronger from the financial crisis. Foreign Aff. 2013, 92, 8-13.

4. Memon, H.; Kumari, N.; Jatoi, A.W.; Khoso, N.A. Study of the indoor decontamination using nanocoated woven polyester fabric. Int. Nano Lett. 2017, 7, 1-7. [CrossRef]

5. Memon, H.; Yasin, S.; Khoso, N.A.; Memon, S. Study of wrinkle resistant, breathable, anti-UV nanocoated woven polyester fabric. Surf. Rev. Lett. 2016, 23, 1650003. [CrossRef]

6. Madjidov, S.; Khakimov, B. Viewpoints about potential stimulation and possibilities of investments on textile industry Uzbekistan. Eur. J. Bus. Econ. 2012, 6, 22-24. [CrossRef]

7. Christopher, M. Logistics E Supply Chain Management; Pearson UK: London, UK, 2016.

8. Dulebenets, M.A. A comprehensive multi-objective optimization model for the vessel scheduling problem in liner shipping. Int. J. Prod. Econ. 2018, 196, 293-318. [CrossRef]

9. Fernie, J.; Sparks, L. Logistics and Retail Management: Emerging Issues and New Challenges in the Retail Supply Chain; Kogan Page Publishers: London, UK, 2018.

10. Zhen, L.; Liang, Z.; Dan, Z.; Lee, L.H.; Chew, E.P. Daily berth planning in a tidal port with channel flow control. Trans. Res. Part B Methodol. 2017, 106, 217. [CrossRef]

11. Umang, N.; Bierlaire, M.; Erera, A.L. Real-time management of berth allocation with stochastic arrival and handling times. J. Sched. 2017, 20,67-83. [CrossRef]

12. Dulebenets, M.A. A Delayed Start Parallel Evolutionary Algorithm for just-in-time truck scheduling at a cross-docking facility. Int. J. Prod. Econ. 2019, 212, 236-258. [CrossRef]

13. Kusiak, A. Smart manufacturing. Int. J. Prod. Res. 2018, 56, 508-517. [CrossRef]

14. Tidd, J.; Bessant, J.R. Managing Innovation: Integrating Technological, Market and Organizational Change; John Wiley \& Sons: Hoboken, NJ, USA, 2018.

15. Oliveira, U.R.D.; Espindola, L.S.; Silva, I.R.D.; Silva, I.N.D.; Rocha, H.M. A systematic literature review on green supply chain management: Research implications and future perspectives. J. Clean. Prod. 2018, 187, S0959652618307406. [CrossRef]

16. Ross, D.F. Transportation management. In Distribution Planning and Control; Chapman \& Hall: London, UK, 1996; pp. 687-760. 
17. Akintoye, A.; McIntosh, G.; Fitzgerald, E. A survey of supply chain collaboration and management in the UK construction industry. Eur. J. Purch. Supply Manag. 2000, 6, 159-168. [CrossRef]

18. Xiang, X.; Liu, C.; Miao, L. Reactive strategy for discrete berth allocation and quay crane assignment problems under uncertainty. Comput. Ind. Eng. 2018, 126, 196-216. [CrossRef]

(C) 2019 by the authors. Licensee MDPI, Basel, Switzerland. This article is an open access article distributed under the terms and conditions of the Creative Commons Attribution (CC BY) license (http://creativecommons.org/licenses/by/4.0/). 